\title{
Studies of obesity, body image and related health issues among Australian adolescents: how can programs in schools interact with and complement each other?
}

\author{
Jennifer A O’Dea \\ Associate Professor in Health Education \\ and Nutrition Education \\ Faculty of Education and Social Work \\ University of Sydney \\ Australia
}

\begin{abstract}
This article details recent studies of body weight, obesity, body image and related health issues among Australian adolescents and the ways in which subsequent nutrition and physical activity programs in schools can interact with and complement each other, rather than contradicting or competing with each other. I briefly identify and discuss the commonalities between health promotion, obesity prevention, body image improvement, eating disorder prevention and promotion of physical activity. In this article I present for the first time the findings of a 2009 research study examining the recent barriers to participation in sport, physical education and physical activity from a study of 1000 Australian children and adolescents. These findings illustrate the complex interrelationships between various adolescent health issues and their prevention. Finally, I believe that preventing the co-existing problems of obesity, low physical activity, disordered eating and body image concerns among adolescents is very challenging and requires a thoughtful, careful community involvement strategy. I suggest that it would be a mistake to target any sort of weight loss or weight control message towards adolescent girls, many of whom clearly already have a fear of fatness, an apparent body image problem and low self-esteem. Similarly, I recommend that it would be culturally inappropriate to approach obesity prevention among ethnic groups of overweight or obese adolescents and their families without serious
\end{abstract}


consideration of the potentially harmful, undesirable or culturally inappropriate outcomes. Several facets of prevention need attention when focusing on school-based health promotion, nutrition education and body image improvement using a whole-school approach, including school curricula, school ethos, school policies and school-community links.

\section{Introduction}

School-based nutrition education for children and adolescents is a very important issue today, as child growth, brain development, academic potential, and current and future health status all depend largely on the quality and quantity of food consumed. Adolescence is a particularly important time of rapid physical growth and development, and the enormous pubertal increases in height, weight, lean muscle mass, fat, organ size and bone density laid down in the teenage years require large nutritional intakes.

In addition to the challenge of educating the population about optimum food and nutrient intakes in childhood and adolescence, another important issue in current nutrition education research and practice is childhood obesity prevention. The importance of identifying cultural and ethnic issues in the management and prevention of weight-related disease has recently been recognised by Lawton and her colleagues (2006) who studied the cultural beliefs and attitudes of people with type 2 diabetes from ethnic minorities living in the United Kingdom.

It is important to note that, whilst the imminent risk of any illness in obese children or teenagers is not considered high (Flegal, Tabak and Ogden 2006), the risk of developing insulin resistance and type 2 diabetes is considered more likely and serious, and some obese adolescents have already been diagnosed with these conditions (Fagot-Campagna et al. 2000). The vast majority of such cases, whilst small in actual number, have been diagnosed among adolescents who are both obese and sedentary (Drake et al. 2002), who have a strong family history of type 2 diabetes and who often come from Indian, Pakistani (Ehtisham, Barrett and Shaw 2000) or African-American or Native-American backgrounds. Similarly, about half of the 43 cases of type 2 diabetes and related conditions identified over the 12 years from 1990 to 2002 in children and adolescents in Western Australia were found among Aboriginal children (McMahon et al. 2004). A recent study of all medical register data on type 2 diabetes in children and adolescents aged 7-18 years in the state of New South Wales (Craig et al. 2001) found 128 cases over the six years from 2001 to 2006. The authors reported that 90 per cent of cases were overweight or obese. Aboriginal children were six times more likely to have type 2 diabetes than their non-Indigenous peers and 75 per cent of those with type 2 diabetes had a family history of the disease. Whilst ethnic and familial effects on type 2 diabetes risk are not always apparent (Wiegand et al. 2004), they remain important risk factors. 


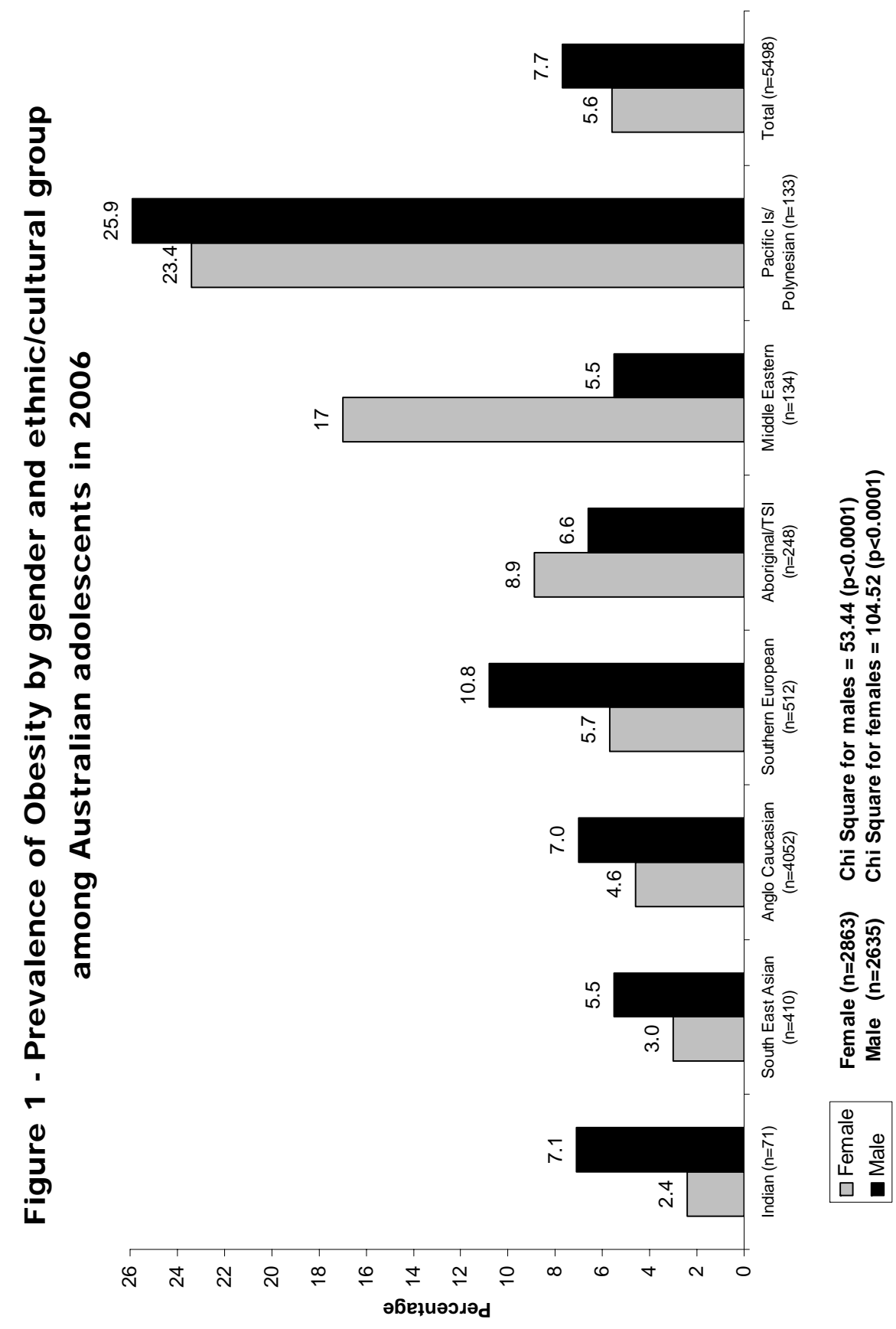


Hence, the study of childhood obesity and its implications for child health in our communities should include a realistic assessment of body composition, overall health status, the risk of actually developing any illness, ethnicity and family background.

Figure 1 illustrates the clear ethnic/cultural trend in obesity prevalence among different ethnic groups. The study included 5498 adolescents aged 12-18 years in Australia in 2006 (O’Dea 2008). More adolescent males were obese than females (7.7\% versus 5.7\%). Obesity was more prevalent among adolescents from Pacific Islander backgrounds. Adolescents who were most likely to be obese were boys and girls of low socioeconomic status (SES) or Pacific Islander or Middle Eastern/Arabic background. The least likely to be obese were Anglo/Caucasian or Asian/Indian students, and in particular the girls. Conversely, this study identified 4 per cent of children and adolescents as 'thin' and this number is identical to the findings of the 2007 national government survey of Australian schoolchildren (Ferrar and Olds 2010).

\section{Body image among Australian adolescents}

Body image is an important issue to consider in any health promotion campaign because it is known to interrelate with actual body weight, obesity, physical activity and disordered eating.

Research into body image among adolescents over the past four decades has shown a continual progression towards a more distorted and negative perception of the body, despite most adolescents being of a normal body weight. Body image emerged as the top concern among the 29,000 young people aged 11-24 years who participated in the Mission Australia 2007 National Survey of Young Australians (Mission Australia 2007). The top three issues of concern nationally were body image, family conflict and coping with stress.

Body image was of significant concern to about one in three (32.3\%) young people, up slightly from 28.1 per cent in 2006. While the level of concern regarding this issue has remained constant for young males (27.9\%) and for those aged 11 to 19 years (around 32\%), it has increased for young females and for those aged 20 to 24 years. Young adults' level of concern about this issue has doubled between 2006 and 2007 to 32.0 per cent. Young women's level of concern about body image has increased from 28.5 per cent in 2006 to 34.9 per cent in 2007.

The top three issues of concern in 2007 for Indigenous respondents in the Mission Australia 2007 national survey were body image, alcohol and family conflict. With the exception of alcohol these were also the main issues of concern for nonIndigenous respondents. Body image was the top issue of concern for both Indigenous and non-Indigenous respondents, with around one in three in both groups identifying it as a major concern.

Studies of Australian adolescents (O’Dea and Abraham 1999a, 1999b) and pubertal girls (Abraham and O'Dea 2001) consistently show an increase in body image concerns and body dissatisfaction around the onset of puberty. This is particularly 
pronounced among girls who become naturally rounder and 'fatter' pre-pubertally and lay down more body fat after their first menstrual period.

Hence, providing effective advice and education about stages of pubertal growth and development and the normal developments experienced by girls and boys during the adolescent growth spurt is a very important role for those who work with young people. Adolescents need to learn that what is happening to their bodies is normal and expected.

Adolescents from different ethnic backgrounds in western societies hold fairly stereotypical perceptions and attitudes towards body satisfaction and body weight with the slim female ideal and the muscular male ideal dominating the body image of most young people. Eating disorders are found among all ethnic groups of adolescents and there are no known cultural or ethnic boundaries. Ethnic influences on self-perception and body image have not been investigated thoroughly among Australian adolescents, but it does seem that the slim ideal for young females (Paxton et al. 1999; O’Dea 1998, 1999) and the larger, muscular ideal for males (McCreary and Sasse 2000) exist throughout cultural and ethnic groups of young first-year university students. Several researchers have found a larger, rounder ideal body among young women from Maori or Pacific Islander backgrounds and this finding has been reiterated among Australian adolescents in the recent National Youth Cultures of Eating Study conducted in 2006. The body image of male and female adolescents from the recent National Youth Cultures of Eating Study conducted in 2006 is presented in Table 1.

Table 1: Body image of Australian adolescents by ethnic/cultural group in 2006

\begin{tabular}{|c|c|c|c|c|c|c|c|c|}
\hline \multirow[b]{2}{*}{$\begin{array}{l}\text { Ethnic/ } \\
\text { cultural } \\
\text { group }\end{array}$} & \multicolumn{3}{|c|}{ Male $(n=2635)$} & \multirow[b]{2}{*}{$\begin{array}{l}\text { Chi } \\
\text { square }\end{array}$} & \multicolumn{2}{|c|}{ Female $(n=2863)$} & \multirow[b]{2}{*}{$\begin{array}{l}\text { 'Too } \\
\text { fat' } \\
\%(n)\end{array}$} & \multirow[b]{2}{*}{$\begin{array}{l}\text { Chi } \\
\text { square }\end{array}$} \\
\hline & $\begin{array}{l}\text { 'Too } \\
\text { thin’ } \\
\%(n)\end{array}$ & $\begin{array}{l}\text { 'About } \\
\text { right' \% } \\
\text { (n) }\end{array}$ & $\begin{array}{l}\text { 'Too } \\
\text { fat' \% } \\
\text { (n) }\end{array}$ & & $\begin{array}{l}\text { 'Too } \\
\text { thin' } \\
\%(n)\end{array}$ & $\begin{array}{l}\text { 'About } \\
\text { right' \% } \\
\text { (n) }\end{array}$ & & \\
\hline $\begin{array}{l}\text { Anglo/ } \\
\text { Caucasian }\end{array}$ & $\begin{array}{l}8.8 \\
(172)\end{array}$ & $\begin{array}{l}76.7 \\
(1499)\end{array}$ & $\begin{array}{l}14.5 \\
(283)\end{array}$ & $38.26 * * *$ & $\begin{array}{l}3.9 \\
(77)\end{array}$ & $\begin{array}{l}70.0 \\
(1378)\end{array}$ & $\begin{array}{l}26.1 \\
(514)\end{array}$ & $32.5^{* *}$ \\
\hline $\begin{array}{l}\text { Aboriginal/ } \\
\text { TSI }\end{array}$ & $\begin{array}{l}13.0 \\
(18)\end{array}$ & $\begin{array}{l}72.5 \\
(100)\end{array}$ & $\begin{array}{l}14.5 \\
(120)\end{array}$ & & $\begin{array}{l}6.8 \\
(10)\end{array}$ & $\begin{array}{l}71.4 \\
(105)\end{array}$ & $\begin{array}{l}21.8 \\
(32)\end{array}$ & \\
\hline $\begin{array}{l}\text { Southern } \\
\text { European/ } \\
\text { Mediterranean }\end{array}$ & $\begin{array}{l}14.3 \\
(28)\end{array}$ & $\begin{array}{l}68.4 \\
(134)\end{array}$ & $\begin{array}{l}17.3 \\
(34)\end{array}$ & & $\begin{array}{l}3.3 \\
(10)\end{array}$ & $\begin{array}{l}72.3 \\
(222)\end{array}$ & $\begin{array}{l}24.4 \\
(75)\end{array}$ & \\
\hline Asian & $\begin{array}{l}17.8 \\
(36)\end{array}$ & $\begin{array}{l}69.3 \\
(140)\end{array}$ & $\begin{array}{l}12.4 \\
(25)\end{array}$ & & $\begin{array}{l}8.5 \\
(17)\end{array}$ & $\begin{array}{l}72.1 \\
(145)\end{array}$ & $\begin{array}{l}19.4 \\
(39)\end{array}$ & \\
\hline $\begin{array}{l}\text { Middle } \\
\text { Eastern }\end{array}$ & $6.5(2)$ & $71.0(22)$ & $\begin{array}{l}22.5 \\
(7)\end{array}$ & & $\begin{array}{l}4.0 \\
(4)\end{array}$ & $\begin{array}{l}67.7 \\
(67)\end{array}$ & $\begin{array}{l}28.3 \\
(28)\end{array}$ & \\
\hline $\begin{array}{l}\text { Pacific } \\
\text { Islander/ } \\
\text { Polynesian }\end{array}$ & $5.3(3)$ & $71.9(41)$ & $\begin{array}{l}22.8 \\
(13)\end{array}$ & & $\begin{array}{l}5.8 \\
(4)\end{array}$ & $\begin{array}{l}56.5 \\
(39)\end{array}$ & $\begin{array}{l}37.7 \\
(26)\end{array}$ & \\
\hline Indian & $\begin{array}{l}24.1 \\
(7)\end{array}$ & $69.0(20)$ & $6.9(2)$ & & $\begin{array}{l}15.0 \\
(6)\end{array}$ & $\begin{array}{l}62.5 \\
(25)\end{array}$ & $\begin{array}{l}22.5 \\
(9)\end{array}$ & \\
\hline
\end{tabular}

$* * * \mathrm{p}<0.001 \quad * * \mathrm{p}<0.01$ 
Whilst the body image of the adolescents generally reflected their actual weight status, there were some marked differences in body perception and body satisfaction among some ethnic groups of obese females. Obese female adolescents from Aboriginal, Middle Eastern/Arabic and Pacific Islander backgrounds were less likely than their Caucasian or Asian peers to perceive themselves as 'too fat' (O'Dea 2008).

Among obese girls aged 12 years or older, the vast majority of girls from Anglo/Caucasian (83.7\%) and Asian (100\%) backgrounds perceived their weight as 'too fat' but this proportion was lower among obese girls from Aboriginal (72.7\%), Southern European (70.6\%), Middle Eastern/Arabic (40\%) and Pacific Islander (73.3\%) background who were significantly less likely to perceive themselves as 'too fat'. The majority of obese Middle Eastern/Arabic girls (60\%) perceived their weight as 'about right'.

The ethnic difference between the body image perceptions of obese adolescent boys was not as clear as those differences among the same grouping of girls. Among obese boys aged 12 years or older, the percentage with a self-perception of 'too fat' was Anglo/Caucasian (65.7\%), Aboriginal (55.6\%), Southern European (61.9\%), Middle Eastern (66.7\%) and Pacific Islander (64.3\%).

An interesting finding of the current study was the apparent lack of concern and significant level of body satisfaction among obese children from Middle Eastern and Pacific Islander backgrounds. Among obese boys of all ages, only half considered their weight to be 'too fat'. This may reflect a desire for 'bigness', muscularity, strength or masculinity among boys and young men which has been previously identified (Tiggemann 2002; McCreary, Saucier and Courtenay 2005). This acceptance of obesity may also reflect social class mores, sporting aspirations or some other socially derived perception or desire for 'bigness' among young males.

The body image findings among girls were equally surprising and interesting, with one third of the obese Aboriginal, Pacific Islander and Southern European girls seeing their weight as acceptable and possibly even desirable. This trend was marked in the obese Middle Eastern girls, two thirds of whom perceived their weight to be about right, and it was glaringly absent in the obese girls from Anglo/Caucasian and Asian backgrounds, with nearly 100 per cent of these girls seeing themselves as 'too fat'.

The body image differences of the young people in this study may reflect cultural body ideals, western ideals of feminine beauty such as the slim ideal, masculinity or socially constructed gender roles. The limitations of the BMI as an instrument of fat measurement among growing children and adolescents must not be excluded as a factor in the determination of these findings, as people from Polynesian backgrounds are known to be tall and muscular (Swinburn et al. 1999) and this might contribute to their greater weight for height, in addition to their body fat.

Clearly, not all obese adolescents perceive their weight to be excessive, unusual or undesirable and health professionals, educators and those working with young 
people should take this into account when dealing with weight issues among adolescents. Another clear recommendation from the 2006 Youth Cultures of Eating Study findings was the need to consider Indigenous cultural issues in school education programs that focus on weight, shape or obesity education, as the Indigenous children and adolescents in the study clearly desired a bigger body than their non-Indigenous peers (Cinelli and O’Dea 2009; McCabe et al. 2005; Mellor et al. 2004).

\section{Social class influences on body weight and body image}

Few studies have properly examined the relationship between socioeconomic status (SES) and body image. Studies from the United States show that those of lower socioeconomic status have a higher prevalence of overweight and obesity (Laitinen, Power and Jarvelin 2001) and this trend has also been found in studies of Australian children and adolescents (O'Dea and Wilson 2006). The literature presents conflicting results on this issue. The majority of studies have found that socioeconomic status is not related to eating disorders, low body satisfaction, poor body image, dieting to lose weight or disordered eating among females. Story et al. (1991) obtained body image information from adolescents in the USA and found no difference in any measure between urban, suburban or rural youth. A study of Australian teenage girls revealed no difference between girls from upper or lower socioeconomic groups for measures of body image or of eating behaviours (O'Dea 1994).

Research linking physical attractiveness reported by others, perceived physical attractiveness, body weight and height to self-concept indicates that adolescent selfconcept is strongly influenced by body weight and perceived body weight.

The most potent influence on self-concept is body weight, and this has a particularly negative influence on the self-concepts of females with the greater the perception of being overweight, the lower the body satisfaction and self-esteem among adolescents. Overweight adolescents or those who perceive themselves as such have lower body satisfaction and self-esteem than normal weight adolescents or those that perceive themselves as such.

\section{Dangerous weight control in adolescents in the 2006 National Youth Cultures of Eating Study}

Recent disordered eating practices reported by adolescent girls in the 2006 National Youth Cultures of Eating Study are given by age group in Table 2.

Disordered eating practices were present among young girls aged 12-16 years but were significantly more prevalent among older girls. Prevalence was 2-3 per cent among male secondary school students. 
Table 2: Comparison of disordered eating behaviours of female adolescents aged 12-15 years and 16-18 years in 2006

\begin{tabular}{llll} 
& $\begin{array}{l}12-15 \text { years }(\mathrm{n}= \\
2489) \%(\mathrm{n})\end{array}$ & $\begin{array}{l}16-18 \text { years } \\
(\mathrm{n}=396) \%(\mathrm{n})\end{array}$ & $\begin{array}{l}\text { Chi } \\
\text { square }\end{array}$ \\
\hline Fasting for two days or more & $14.7(346)$ & $18.0(71)$ & $4.2^{*}$ \\
Laxative abuse & $2.2(52)$ & $3.0(12)$ & 1.4 \\
$\begin{array}{l}\text { Smoking for appetite } \\
\text { suppression and weight control }\end{array}$ & $3.7(88)$ & $12.6(50)$ & $60.1^{* * *}$ \\
$\begin{array}{l}\text { Vomiting } \\
\text { Chewing food but not }\end{array}$ & $7.2(170)$ & $12.9(50)$ & $16.8^{* * *}$ \\
swallowing & $2.2(53)$ & $3.5(14)$ & 3.0 \\
Slimming pills & $1.7(40)$ & & \\
\hline$* \mathrm{p}<0.05 \quad * * * \mathrm{p}<0.001$ & & & \\
\end{tabular}

In the 2006 study, disordered eating behaviours for weight control, such as fasting, laxative abuse, smoking, vomiting, chewing food but not swallowing and slimming pills were dangerously present and frequent in girls as young as 12 years old. There appears to be a sharp increase in these dangerous behaviours after pubertal development, which has been suggested by previous authors. Among older girls, these unhealthy behaviours were more common, with as many as one fifth of 16-19 year old girls regularly fasting for two days or more to try to control their weight.

These numbers are higher than a similar study conducted more than a decade ago (O'Dea, Abraham and Heard 1996) and suggest that eating problems may have been increasing among girls over the past few decades. For example, in our early study of girls aged 11-14 years (O’Dea, Abraham and Heard 1996), we found 9.9 per cent fasting, 3.4 per cent vomiting, 2.4 per cent smoking, 2.2 per cent taking slimming pills, and these percentages compare to $14.7 \%, 7.2 \%, 3.7 \%$ and $1.7 \%$ respectively in the 2006 study of similarly aged girls.

\section{Barriers to sport, physical education and physical activity}

Of similar concern to the weight issues, body image concerns and disordered eating among Australian children and adolescents is low participation in physical education, sport and physical activity, which is particularly common in older girls. As health educators, increasing physical activity among youth is one of our prime roles.

To illustrate the interrelated ways in which preventive efforts that focus around reducing obesity, preventing body image problems and promoting physical activity need to intersect, the following table presents new data from 2009 about the major 
barriers to sport, physical education and physical activity in 690 adolescent boys and 650 girls from 16 New South Wales primary and secondary schools. These new data clearly show the barriers that need to be overcome in order to improve participation in sport and physical activity among schoolchildren. The new data also reflect the previously identified issues of body image concern, teasing and weight stigma that act as barriers to the success of health promotion programs.

Table 3: Major barriers to sport, physical education and physical activity in 690 boys and 650 girls from 16 NSW primary and secondary schools in 2009

What stops you participating in PE, sport or physical activity?
Males $\quad(n=690), \quad$ Females $\quad(n=650)$, $\%$ answering yes \% answering yes

\begin{tabular}{lll}
\hline Prefer to do other things & 24 & 25 \\
Don't like changing & 22 & 25 \\
Self-conscious about body & 18 & 23 \\
Don't have time & 18 & 23 \\
No-one to play with & 15 & 12 \\
Don't want to get hurt & 13 & 16 \\
Too tired & 12 & 15 \\
I am no good at it & 11 & 25 \\
Don't like to be hot and sweaty & 10 & 8 \\
Don't like the training & 9 & 10 \\
I have become bored with it & 9 & 16 \\
My parents don't have time & 8 & 10 \\
Others tease me and laugh at me & 7 & 10 \\
\hline
\end{tabular}

The major perceived barriers to PE, sport and physical activity in this recent sample of Australian children and adolescents was surprisingly similar between the genders, with a preference for other uses of their time; a dislike of changing in front of others and body consciousness being the three major concerns of both girls and boys. 
The influence of body image concerns is quite apparent in these data, suggesting that participation in sport, PE and physical activity may be increased if schools and communities implemented activities to reduce such concerns. Suggested activities could include the provision of varied PE and sports activities; making change rooms private; approving more modest PE and sports uniforms and swimming uniforms; and reducing the need to change uniforms in front of other people.

\section{Preventive approaches}

The prevention of co-existing problems of obesity, low physical activity, disordered eating and body image concerns among adolescents is therefore challenging and requires a thoughtful, careful and community involvement strategy. It would certainly be a mistake to target any sort of weight loss or weight control message towards teenage girls, many of whom clearly already have a fear of fatness, an apparent body image problem and low self-esteem. Similarly, it would be culturally inappropriate to approach obesity prevention among ethnic groups of overweight or obese adolescents and their families without serious consideration of the potentially harmful, undesirable or inappropriate outcomes.

One of the major challenges for those involved in youth health promotion is finding a way to engage big children and teens in physical activity for health and pleasure, without inadvertently delivering an unintended weight control message. Another major challenge is how best to address the barriers to physical activity, such as selfconsciousness and related issues including being able to reduce weight teasing and stigma, as the latter is known to be worsening (Latner and Stunkard 2003). Many theorists suggest the implementation of a size acceptance approach for this purpose.

The current co-occurrence of increasing body image concerns and disordered eating with increasing rates of childhood obesity makes the role of educators, clinicians and community workers complicated because of concerns that we must 'First, Do No Harm' (Garner 1988; Ikeda, Crawford and Woodward-Lopez 2006) in our efforts to ameliorate both issues among adolescents. Those who work with young people need to be careful to ensure that the implementation of programs for the prevention of childhood obesity does not inadvertently create food concerns, body image issues, weight stigma, prejudice or eating disorders. Similarly, eating disorder prevention programs must take care not to condone obesity or to glamorise or normalise dieting or disordered eating. The promotion of physical activity, sport and school PE must first address the barriers to those activities that have been currently identified by young people.

Clearly, a major aim of programs to improve body image, eating problems, physical activity and child obesity is to encourage healthy eating and physical activity among children and adolescents without promoting fad diets, weight loss attempts and the diet-binge cycle. 


\section{A 'whole school' approach to body image improvement and obesity prevention}

Development of a healthy active lifestyle, student self-esteem and media literacy skills for the prevention of body image and eating problems would be very naive if confined to the individual or to the school classroom.

An adolescent's lifestyle and health behaviours, body image, self-esteem and sense of self-worth, whilst certainly affected by school curricula and teaching style, is also impacted by peers (e.g. teasing), attitudes of family, teachers and coaches, school environment, community factors (e.g. the media, advertising, sports involvement), availability of resources and culture (e.g. feminist issues, cultural stereotypes, social norms and stigma about weight and shape).

School policy changes such as anti-teasing/bullying policies are very powerful ways of changing the whole school environment to promote a greater diversity in body shapes and a greater tolerance of individual differences. These improvements are also likely to increase participation in physical activity.

A holistic environmental approach to the prevention of body image and eating problems as well as prevention of child overweight, such as the Health Promoting Schools Framework (World Health Organization 1998), theorises that whole communities need to be involved in fostering overall health within school and community environments. Several facets of prevention need attention when focusing on health promotion, nutrition education and body image improvement using a whole school approach, including school curricula, school ethos, school policies and school-community links.

The perennial challenge for all health educators and those involved in health promotion is the closing of the health gap between SES groups, and in Australia this includes the improvement of health and wellbeing among young people from disadvantaged communities and Indigenous youth. The social determinants of health remain well entrenched in Australia, as some of these research findings indicate, and addressing the social determinants of health among Australian children and adolescents will remain our greatest challenge in the many decades to come.

\section{References}

Abraham, S and O’Dea, J 2001, 'Body mass index, menarche and perceptions of dieting among peri-pubertal adolescent females', International Journal of Eating Disorders, vol. 29, no. 1, pp. 23-28.

Cinelli, RL and O’Dea, JA 2009, 'Body image and obesity among Australian adolescents from Indigenous and Anglo/European backgrounds: implications for health promotion and obesity prevention among Aboriginal youth', Health Education Research, vol. 24, no. 6, pp. 1059-1068. 
Craig, P, Halavatau, V, Comino, E and Caterson, I 2001, 'Differences in body composition between Tongans and Australians: time to rethink the healthy weight ranges?', International Journal of Obesity, vol. 25, pp. 1806-1814.

Drake, AJ, Betts, PR, Crowne, EC and Shield, JP 2002, 'Type 2 diabetes in obese white children', Archives of Diseases in Children, vol. 86, pp. 207-208.

Ehtisham, S, Barrett, TG and Shaw, NJ 2000, 'Type 2 diabetes mellitus in UK children - an emerging problem', Diabetic Medicine, vol. 17, pp. 867-871.

Fagot-Campagna, A, Pettitt, DJ, Engelgau, MM, Burrows, NR, Geiss, LS, Valdez, R et al. 2000, 'Type 2 diabetes among North American children and adolescents: an epidemiologic review and a public health perspective', Journal of Pediatrics, vol. 136, no. 5, pp. 664-672.

Ferrar, K and Olds, T 2010, 'Thin adolescents: Who are they? What do they do? Socio-demographic and use-of-time characteristics', Preventive Medicine, vol. 51, no. 3-4, pp. 253-258.

Flegal, KM, Tabak, CJ and Ogden, CL 2006, 'Overweight in children: definitions and interpretation’, Health Education Research, vol. 21, pp. 755-761.

Garner, DM 1988, 'Intragenesis in anorexia nervosa and bulimia nervosa', International Journal of Eating Disorders, vol. 4, pp. 701-726.

Ikeda, JP, Crawford, PB and Woodward-Lopez, G 2006, 'BMI screening in schools: helpful or harmful?’, Health Education Research, vol. 21, pp. 761-770.

Laitinen, J, Power, C and Jarvelin, MR 2001, 'Family social class, maternal body mass index, childhood body mass index, and age at menarche as predictors of adult obesity', American Journal of Clinical Nutrition, vol. 74, pp. 287-294.

Latner, JD and Stunkard, A 2003, 'Getting worse: stigmatization of obese children', Obesity Research, vol. 11, pp. 452-456.

Lawton, J, Ahmad, N, Hanna, L, Douglas, M and Hallowell, N 2006, 'I can’t do any serious exercise: barriers to physical activity amongst people of Pakistani and Indian origin with type 2 diabetes', Health Education Research, vol. 21, no. 1, pp. 43-54.

McCabe, M, Ricciardelli, L, Mellor, D and Ball, K 2005, 'Media influences on body image and disordered eating among Indigenous adolescent Australians', Adolescence, vol. 40, no. 157, pp. 115-127.

McCreary, DR and Sasse, DK 2000, 'An exploration of the drive for muscularity in adolescent boys and girls', Journal of American College Health, vol. 48, pp. 97-103. 
McCreary, DR, Saucier, DM and Courtenay, WH 2005, 'The drive for muscularity and masculinity: testing the associations among gender role traits, behaviors, attitudes, and conflict', Psychology of Men and Masculinity, vol. 6, pp. 8394.

McMahon, SK, Haynes, A, Ratnam, N, Grant, MT, Carne, CL, Jones, TW and Davis, E 2004, 'Increase in type 2 diabetes in children and adolescents in Western Australia’, Medical Journal of Australia, vol. 180, no. 9, pp. 459461.

Mellor, D, McCabe, M, Ricciardelli, L and Ball, K 2004 'Body image importance and body dissatisfaction among Indigenous Australian adolescents', Body Image, vol. 1, pp. 289-297.

Mission Australia 2007, National survey of young Australians 2007: key and emerging issues, Mission Australia, Sydney.

O’Dea, J 1994, 'Food habits, body image and self-esteem of adolescent girls from disadvantaged and non-disadvantaged backgrounds', Australian Journal of Nutrition and Dietetics, vol. 51, pp. 74-78.

O’Dea, J 1998, 'The body size preferences of underweight young women from different cultural backgrounds', Australian Journal of Nutrition and Dietetics, vol. 55, pp. 75-80.

O’Dea, J 1999, 'Cross-cultural, body weight and gender differences in the body size perceptions and body ideals of university students', Australian Journal of Nutrition and Dietetics, vol. 56, no. 3, pp. 144-150.

O’Dea, JA 2008, ‘Gender, ethnicity, culture and social class influences on childhood obesity among Australian schoolchildren: implications for treatment, prevention and community education', Journal of Health \& Social Care in the Community, vol. 16, no. 3, pp. 282-290.

O’Dea, JA and Abraham, S 1999a, ‘Association between self-concept and body weight, gender, and pubertal development among male and female adolescents', Adolescence, vol. 34, pp. 69-79.

O’Dea, JA and Abraham, S 1999b, 'Onset of disordered eating attitudes and behaviors in early adolescence: interplay of pubertal status, gender, weight, and age', Adolescence, vol. 34, no. 136, pp. 671-679.

O’Dea, J, Abraham, S and Heard, R 1996, 'Food habits, body image and weight control practices of young male and female adolescents', Australian Journal of Nutrition and Dietetics, vol. 53, pp. 32-38.

O’Dea, JA and Wilson, R 2006, 'Socio-cognitive and nutritional factors associated with body mass index in children and adolescents: possibilities for childhood 
obesity prevention', Health Education Research: Theory and Practice, vol. 21. no. 6, pp. 796-806.

Paxton, SJ, Schutz, HK, Wertheim, EH and Muir, SL 1999, 'Friendship clique and peer influences on body image concerns, dietary restraint, extreme weightloss behaviours, and binge eating in adolescent girls', Journal of Abnormal Psychology, vol. 108, no. 2, pp. 255-266.

Story, M, Rosenwinkel, K, Himes, JH, Resnick, M, Harris, LJ and Blum, RW 1991, 'Demographic and risk factors associated with chronic dieting in adolescents', American Journal of Diseases in Children, vol. 145, pp. 994-998.

Swinburn, BA, Ley, SJ, Carmichael, HE and Plank, LD 1999, 'Body size and composition in Polynesians', Int J Obes Relat Metab Disord, vol. 23, pp. 1178-1183.

Tiggemann, M 2002, 'Media influences on body image development' in Body image: a handbook of theory, research and clinical practice, ed. TF Cash and T Pruzinsky, Gulliford Press, New York, pp. 91-98.

Wiegand, S, Maikowski, U, Blankenstein, O et al. 2004, 'Type 2 diabetes and impaired glucose tolerance in European children and adolescents with obesity - a problem that is no longer restricted to minority groups', European Journal of Endocrinology, vol. 151, pp. 199-206.

World Health Organization 1998, Health promoting schools: a healthy start for living, learning and working, WHO, Geneva.

\section{Acknowledgements}

The study in 2000 was funded by a research grant from Kellogg Australia. The 2006 study was funded by an ARC Discovery grant (Probyn and O’Dea, 'National Youth Cultures of Eating Study', 2005-2007). The 2007-2010 study was funded by an ARC Discovery grant (Lumby, Probyn and O’Dea). 